Research Article

\title{
Electronic Structure and Energy Band of IIIA Doped Group ZnO Nanosheets
}

\author{
Xian-Yang Feng, Zhe Wang, Chang-Wen Zhang, and Pei-Ji Wang \\ School of Physics, University of Jinan, Jinan 250022, China \\ Correspondence should be addressed to Pei-Ji Wang; ss_wangpj@ujn.edu.cn
}

Received 7 March 2013; Revised 8 May 2013; Accepted 26 May 2013

Academic Editor: Huiwen Xu

Copyright (C) 2013 Xian-Yang Feng et al. This is an open access article distributed under the Creative Commons Attribution License, which permits unrestricted use, distribution, and reproduction in any medium, provided the original work is properly cited.

\begin{abstract}
The electronic and magnetic properties of IIIA group doped $\mathrm{ZnO}$ nanosheets ( $\mathrm{ZnONSs}$ ) are investigated by the first principles. The results show that the band gap of $\mathrm{ZnO}$ nanosheets increases gradually along with $\mathrm{Al}, \mathrm{Ga}$, and In ions occupying $\mathrm{Zn}$ sites and $\mathrm{O}$ sites. The configuration of $\mathrm{Al}$ atoms replacing $\mathrm{Zn}$ atoms is more stable than other doped. The system shows half-metallic characteristics for In-doped $\mathrm{ZnO}$ nanosheets.
\end{abstract}

\section{Introduction}

As one of the wide-band-gap oxides, $\mathrm{ZnO}$ has received considerable interest for its wide variety of practical applications, such as liquid crystal display transistors, gas sensors, and ferroelectric transparent thin-film transistors [1-6]. More interest in IIIA-doped $\mathrm{ZnO}$ arose because of the hope of improving both electron conductivity and room-temperature ferromagnetism [7-9]. The room temperature ferromagnetism was reported by Dietl et al. (2000) in Mn-doped $\mathrm{ZnO}$. After that, many researchers have doped $\mathrm{ZnO}$ with 3d transition metal and reported high room temperature ferromagnetism. There have been also a lot of theoretical and computational studies in IIIA-doped $\mathrm{ZnO}[10,11]$.

In general, the electron conductivity of pure $\mathrm{ZnO}$ is not low enough to be used as a transparent conductive oxide (TCO). It is necessary that the behavior of the $\mathrm{ZnO}$ must be changed effectively by substitutional doping into $\mathrm{ZnO}$. Zuo et al. [12] study the effect of C-Al (Ga) codoping on p-type tendency in zinc oxide. They indicated that the volume of $\mathrm{C}$ doped $\mathrm{ZnO}$ and $\mathrm{C}-\mathrm{Ga}$ codoped $\mathrm{ZnO}$ swells up a little and that of $\mathrm{ZnO}$ by $\mathrm{C}-\mathrm{Al}$ codoping decreases slightly. Liu et al. [13] found out that the band gap of $\mathrm{ZnO}$ is reduced by In doping. Stimulated by the discovery of carbon nanotubes, various functional $\mathrm{ZnO}$ nanostructures have recently been synthesized [14-19]. These nanostructures are expected to find applications in optoelectronics, sensors, transducers, and biomedical science. Particularly, two-dimensional (2D) systems show peculiar properties which are different from their counterpart bulk phases.

In the present work, we explored the electronic properties of $\mathrm{ZnO}$ doped with IIIA ions ( $\mathrm{Al}, \mathrm{Ga}$, and $\mathrm{In}$ ) based on firstprinciples calculations to the $\mathrm{ZnO}$ nanosheets ( $\mathrm{ZnONSs}$ ). These studies provide us with a deep understanding of the novel properties of intrinsic defect $\mathrm{ZnO}$ nanosheets, which is essential to employ $\mathrm{ZnO}$ nanosheet as building blocks for the future nanodevices.

\section{Computational Details}

We use first-principles full-potential linearized augmented plane wave (FLAPW) method based on the generalized gradient approximation (GGA) [20] for the exchange-correlation potential within the framework of density-functional theory [21] to perform the computations. It was implemented in the WIEN2K simulation package, in order to investigate the electronic and magnetic properties of $2 \mathrm{D} \mathrm{ZnO}$. Atomic sphere radii of $\mathrm{Zn}, \mathrm{O}$ are set to $1.9,1.7$ a.u., respectively. The valence electrons for the $\mathrm{Zn}, \mathrm{O}$ are $12\left(\mathrm{Zn}: 3 \mathrm{~d}^{10} 4 \mathrm{~s}^{2}\right), 6\left(\mathrm{O}: 2 \mathrm{~s}^{2} 2 \mathrm{p}^{4}\right)$. The parameter $R_{\min } K_{\max }$, which controls the size of the basis set in our calculations, is chosen as 6.0. $R_{\min }$ is the minimum sphere radius and $K_{\max }$ is the maximal value of the reciprocal lattice vector used in the plane wave expansion. The Brillouin zone (BZ) is represented by the set of $6 \times 6 \times 1 \mathrm{k}$-points for 
the geometry optimizations and for the static total energy calculations. The structural relaxation is done until the forces on each atom are smaller than $10^{-2} \mathrm{eV} / \AA$.

\section{Results and Discussion}

3.1. Model Structures and Relative Stability of IIIA Ions Doped $\mathrm{ZnONSs}$. The $\mathrm{ZnO}$ is wurtzite structure, in which all atoms are in $\mathrm{sp}^{3}$ hybridization with each $\mathrm{Zn}(\mathrm{O})$ atom surrounded by four neighboring $\mathrm{O}(\mathrm{Zn})$ atoms at the corners of a tetrahedron. The $\mathrm{Zn}-\mathrm{O}$ bond length is calculated to be $1.973 \AA$, in good agreement with the values of $1.86 \AA$ by Tu [22] and 1.90 Å by Topsakal et al. [23].

First we consider a 3D wurtzite bulk $\mathrm{ZnO}$ structure in which all atoms are fourfold coordinated through hexagonal directed $\mathrm{sp}^{3}$ orbital. After optimization, the hexagonal lattice constants under equilibrium are $a=b=3.246 \AA, c=$ $5.200 \AA$, which is used for constructing the nanostructure. Figure 1 shows the band structure of $3 \mathrm{D} \mathrm{ZnO}$ crystal. It can be seen that bulk $\mathrm{ZnO}$ is a direct band gap semiconductor. The calculated band gap at the $\Gamma$ point is $0.84 \mathrm{eV}$, which is smaller than the experimental value. This underestimation is due to the GGA approximation, which does not consider the noncontinuity of the exchange correlation, which does not affect our theoretical analysis, because it does not impact the variation trend of other electronic and optical properties. We focus on the relative value of band gap mainly.

Next we studied 2D nanosheets derived from wurtzite $\mathrm{ZnO}$. The nanosheets are based on the model of $(2 \times 2)$ supercell cut from initial bulk $\mathrm{ZnO}$ (0001) plane, which contains $9 \mathrm{Zn}$ and $9 \mathrm{O}$ atoms, as shown in Figure 2. After full optimization, the pristine $\mathrm{ZnONSs}$ transform from the initial configuration (Figure 2(a)) to a flat graphitic structure (Figure 2(b)). For the structural optimization, the energetic convergence threshold is $10^{-4} \mathrm{Ry}$. Atomic relaxation is carried out until all components of the residual forces are less than $1 \mathrm{mRy} / \mathrm{a}$.u. A pronounced geometry change appears in this case: the length of $\mathrm{Zn}-\mathrm{O}$ bond has changed from 1.973 to $1.876 \AA$. Moreover, the bond angle within the newly formed planar layer increases from the wurtzite tetrahedral, $109^{\circ}$ on average, to plane trigonal, $120^{\circ}$.

We also find that the calculated band structure of the ZnONSs exhibits a direct band gap at the $\Gamma$ point with an energy gap of $1.40 \mathrm{eV}$, which is bigger than that in the bulk structure. The spin-polarized calculations show that the ZnONSs have no magnetism; this can also be seen from the total density of states (DOS) shown in Figure 2 and is consistent with previous experimental results $[23,24]$.

For the structures that are doped, we considered two configurations: one IIIA ion replacing one $\mathrm{Zn}$ atom $(\mathrm{M}-\mathrm{Zn})$ and $\mathrm{O}$ atom $(\mathrm{M}-\mathrm{O})$. Figure 3 shows the evolution of band gap as a function of IIIA ions. The band gap values are 0.43 , 0.66 , and $0.87 \mathrm{eV}$ for $\mathrm{M}-\mathrm{Zn}$ and $0.47,0.53$, and $0.81 \mathrm{eV}$ for $\mathrm{M}-$ $\mathrm{O}$, respectively, which are smaller than the band gap of bulk $\mathrm{ZnO}$ doped with $\mathrm{Al}, \mathrm{Ga}$, and $\mathrm{In}(1.75,1.81$, and $1.86 \mathrm{eV})$ [25]. This is an indication of quantum size effect. The atom radii of $\mathrm{Al}, \mathrm{Ga}$, and In are increasing gradually, result in the bond length of $\mathrm{M}-\mathrm{Zn}$ and $\mathrm{M}-\mathrm{O}$ become smaller; in other words, the bond of $\mathrm{M}-\mathrm{Zn}$ and $\mathrm{M}-\mathrm{O}$ contracted gradually. Due to the

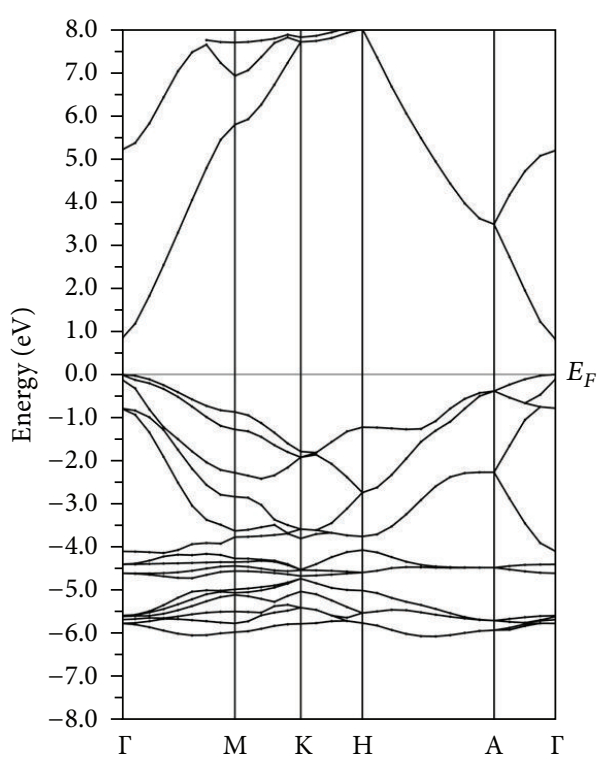

FIgURE 1: Band structure of a 3D bulk $\mathrm{ZnO}$ crystal with an optimized lattice constant. The valence band maximum is set to zero.

TABle 1: Formation energies $(\mathrm{eV})$ of $\mathrm{M}$-doped $(\mathrm{M}=\mathrm{Al}, \mathrm{Ga}, \mathrm{In})$ ZnONSs.

\begin{tabular}{lcc}
\hline \multirow{2}{*}{ Configurations } & \multicolumn{2}{c}{ Formation energies $(\mathrm{eV})$} \\
& $\mathrm{M}-\mathrm{Zn}$ & $\mathrm{M}-\mathrm{O}$ \\
\hline Al-ZnONSs & 3.97 & 5.76 \\
Ga-ZnONSs & 6.60 & 6.81 \\
In-ZnONSs & 7.78 & 8.83 \\
Bulk ZnO & & 1.26 \\
\hline
\end{tabular}

Goldschmidt-Pauling rule [26] of bond contraction induced by undercoordination, this results in the increase of band gap of $\mathrm{M}-\mathrm{Zn}$ and $\mathrm{M}-\mathrm{O}$.

The formation energies of M-doped $\mathrm{ZnONSs}$ were calculated to evaluate their stability. To make comparison, we also calculated the formation energies of bulk $\mathrm{ZnO}$. The formation energy [27] in our work can be expressed as

$$
\begin{aligned}
E_{F}= & E_{\text {tot }}(\mathrm{ZnONSs}: \mathrm{M})+E(\mathrm{Zn}) / E(\mathrm{O}) \\
& -E(\mathrm{M})-E_{\text {tot }}(\mathrm{ZnONSs}),
\end{aligned}
$$

where $E(\mathrm{Zn}), E(\mathrm{O})$, and $E(\mathrm{M})$ represent the chemical potential of $\mathrm{Zn}, \mathrm{O}$ and $\mathrm{M}(\mathrm{M}=\mathrm{Al}, \mathrm{Ga}, \mathrm{In})$, respectively. $E_{\text {tot }}(\mathrm{ZnONSs}: \mathrm{M})$ and $E_{\text {tot }}(\mathrm{ZnONSs})$ are the total energy of Mdoped $\mathrm{ZnONSs}$ and the initial ZnONSs.

Table 1 shows the formation energies of $\mathrm{M}$-doped $(\mathrm{M}=$ $\mathrm{Al}, \mathrm{Ga}, \mathrm{In}) \mathrm{ZnONSs}$. The formation energies of $\mathrm{M}-\mathrm{Zn}$ are all smaller than $\mathrm{M}-\mathrm{O}$; it indicated that the IIIA ions would be more favorable in the $\mathrm{Zn}$ sites than in the $\mathrm{O}$ sites for $\mathrm{M}$-doped $\mathrm{ZnONSs}$. In the following parts, we only consider the properties of the $\mathrm{M}-\mathrm{Zn}$ configurations. For the configurations with IIIA ions replacing $\mathrm{Zn}$ atoms, the formation energy increases with the increase of the IIIA proton number. This indicates that the configuration of Al-ZnONSs is more stable. 


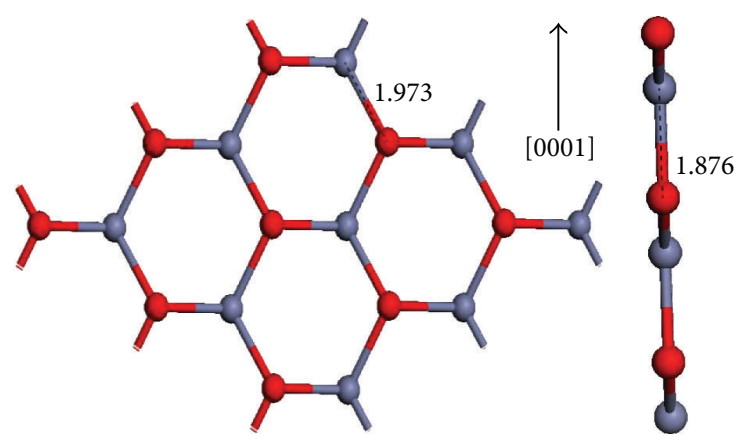

(a)

(b)

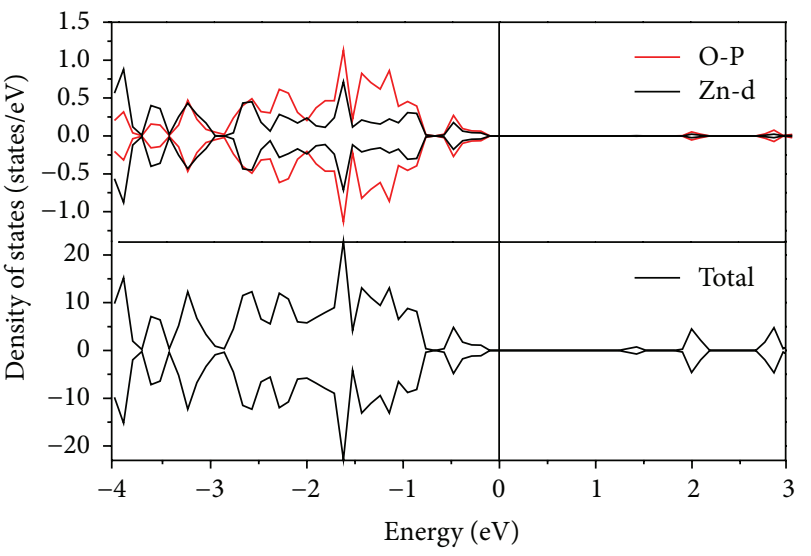

(c)

Figure 2: (a) (Color online) Structure of $\mathrm{ZnO}$ nanosheet, the red ball stands for O atom and the gray one is $\mathrm{Zn}$ atom. (a) Top view of the configuration without being relaxed. (b) Side view of configuration after being relaxed. (c) DOS of the pristine ZnONSs.

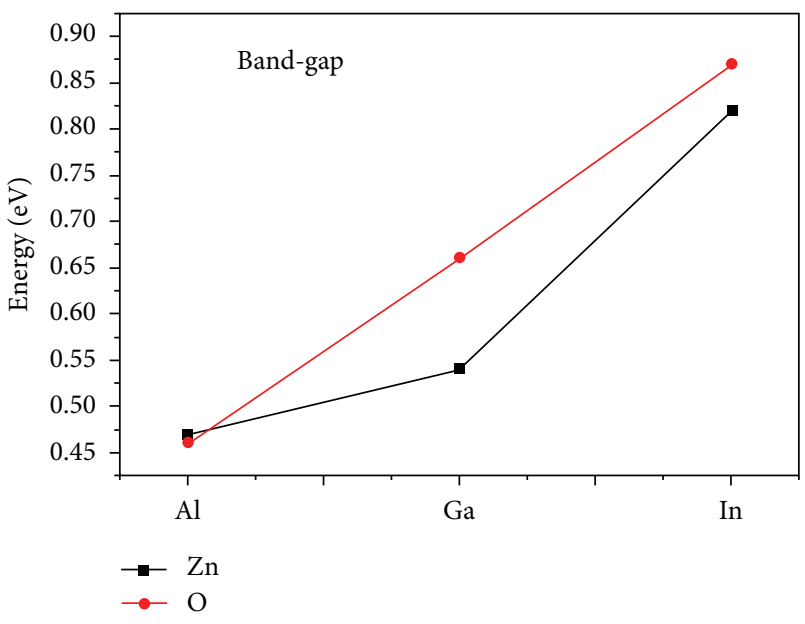

FIGURE 3: Band gap evolution of graphitic nanosheets as a function of $\mathrm{Al}, \mathrm{Ga}$, In.

3.2. Band Structure and Electronic and Magnetic Properties of IIIA Ions Doped ZnONSs. In Figure 4 we show the band structure and total DOS of $\mathrm{Al}, \mathrm{Ga}$, and In doped in $\mathrm{ZnONSs}$. In all cases, spin polarization is evident in the band structure and DOS. Because there is an excess of electrons at the bottom of the conduction bands, $\mathrm{ZnO}$ doped with IIIA elements introduces the n-type carriers into the system; the Fermi level moves into the conductive bands (CBs), which is in good agreement with the experimental results [23]. Figure 4(a) shows the band structure and total DOS of $\mathrm{Al}$ doped in the ZnONSs. It is important to note that the Fermi level $\left(E_{F}\right)$ is largely crossed by spin-down states, while spin-up states only cut $E_{F}$ from the right figure, which indicates that the system belongs to half-metallic ferromagnet. In the spindown states, the impurity bands introduced by Al-doped occupy the energy level at the bottom of the conduction band (CBM) minimum, which shows that Al-doped ZnONSs can lead $\mathrm{ZnO}$ to an n-type semiconductor. Interestingly, when $\mathrm{Ga}$ is doped in the ZnONSs both the spin-up and spindown states become metallic, as can be seen in Figure 4(b), indicating that the $\mathrm{Ga}$ doped in the $\mathrm{ZnONSs}$ are all metals with strong spin polarization. The metallicity of $\mathrm{ZnONSs}$ is characterized by several energy levels crossing over from conduction band to valence band across the Fermi level in the band structure, as well as the peak at the Fermi level in the DOS. After In is doped in the ZnONSs (Figure 4(c)), like Al-doped $\mathrm{ZnONSs}$, the system belongs to half-metallic ferromagnet too. Figure 4(d) shows the band structure of undoped $\mathrm{ZnONSs}$. It indicated that $\mathrm{ZnONSs}$ are a direct band gap semiconductor. There is one impurity band introduced by IIIA element that appeared between valance band and 


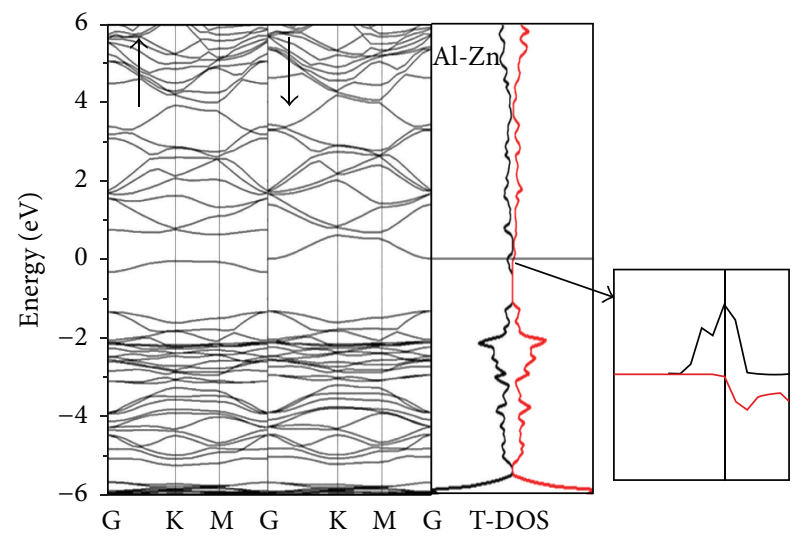

(a)

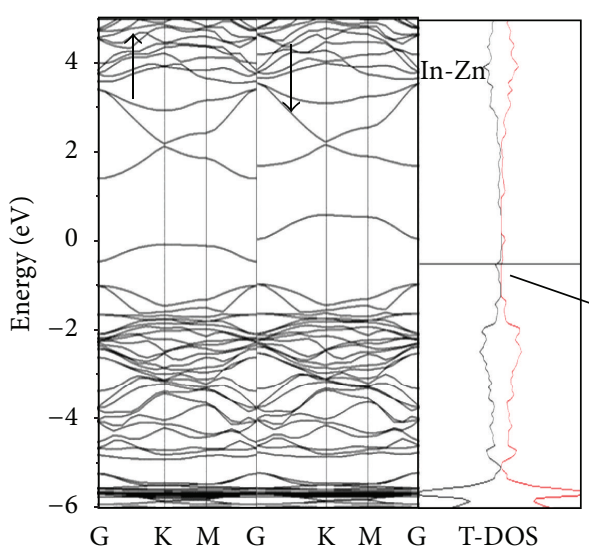

(c)

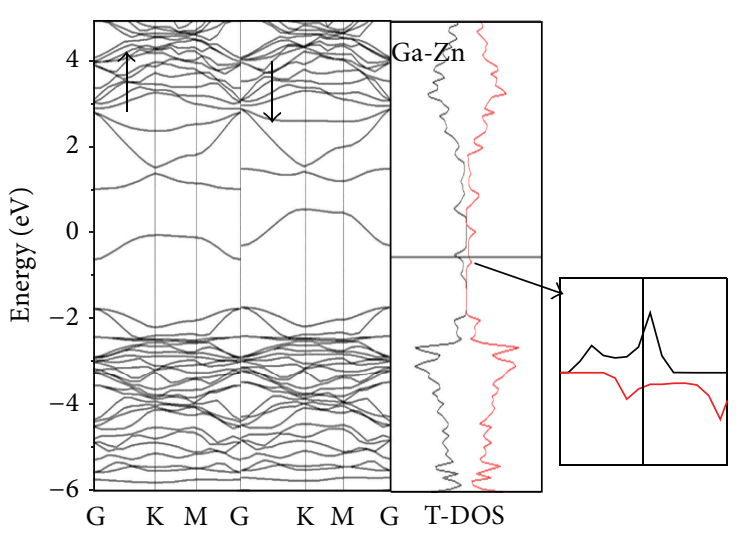

(b)

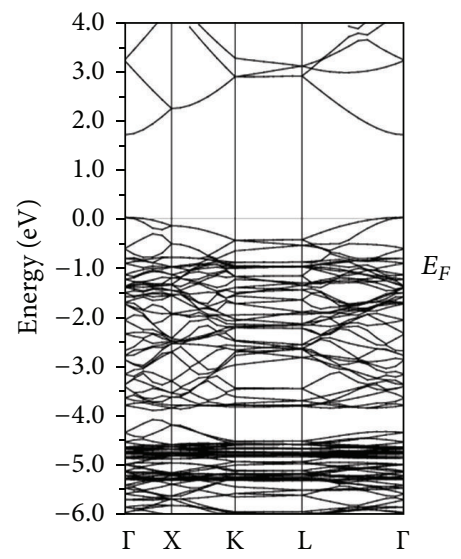

(d)

Figure 4: Band structure, total DOS of (a) Al-doped ZnONSs, (b) Ga-doped ZnONSs, and (c) In-doped ZnONSs, respectively. (d) The band gap of undoped $\mathrm{ZnO}$ nanosheet. The arrows in the energy band mean spin direction.

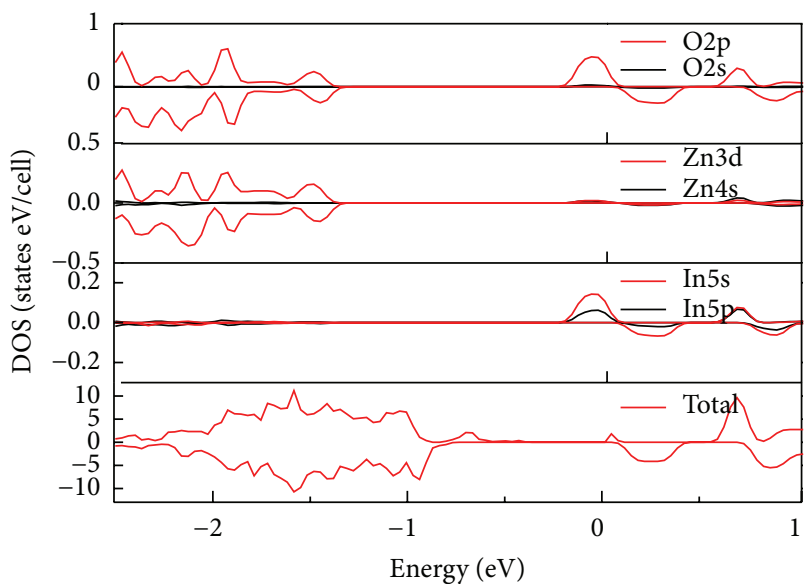

(a)

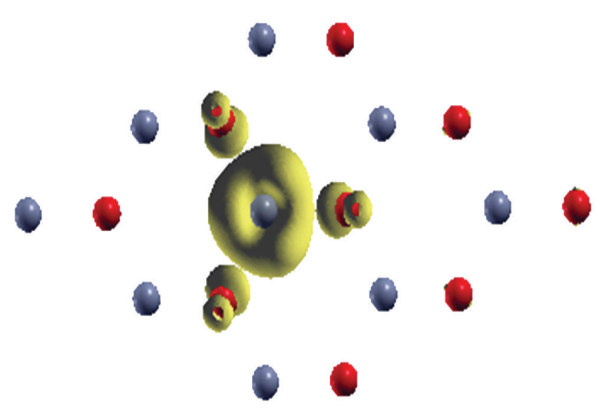

(b)

Figure 5: PDOS (a) and isosurface of spin densities (b) for In-doped ZnONSs. The red ball stands for O atom and the gray one is $\mathrm{Zn}$ atom; the dark gray one is In atom. 
conduct band compared to band structure of undoped ZnONSs.

In order to further explain the origin of the half-metallic ferromagnet, we also give the partial DOS for the In-doped $\mathrm{ZnONSs}$ (Figure 5(a)). It is notable that both the O-2p and In 5 s states are located in the Fermi energy level. It indicates that there exits strong hybridization between the In-5s and O-2p states and the In-O bond is quite covalent instead of being purely ionic. The local density of state from -2.5 to $-0.5 \mathrm{eV}$ is derived largely from the $\mathrm{O}-2 \mathrm{p}, \mathrm{Zn}-3 \mathrm{~d}$ states. It shows a strong $\mathrm{d}$ character and comes mostly from the $\mathrm{Zn}-3 \mathrm{~d}$ states. The broad conduction bands between 0 and $2.5 \mathrm{eV}$ are mainly composed of O-2p which overlap significantly with those of In-5s states near $E_{F}$, suggesting a strong interaction between them.

To analyze spin polarization induced by In doped, we calculated spin density distribution around the In atom of $\mathrm{ZnONSs}$; electrons of In and $\mathrm{O}$ atoms are both spin-polarized, and In-5s and O-2p electrons couple at the Fermi level. As presented in Figure 5(b), defect states wave functions are strongly localized In impurity, with a magnetic moment of $0.97 \mu_{\mathrm{B}}$. The magnetic moments on $\mathrm{Zn}$ and other $\mathrm{O}$ atoms away from the $\mathrm{ZnONSs}$ are smaller than $0.03 \mu_{\mathrm{B}}$. The relevant part of the induced magnetic moment is located on the host oxygen atoms surrounding the impurity, quantitatively, about $90 \%$ of which is concentrated on the three oxygen ions that are the nearest neighbors to the In ion. There is a charge transfer from In to $\mathrm{O}$ atoms, and because of the electron transfer, the long pairs on In are partially unpaired and there are a number of In-5s holes with minority spin states in the In valance band [28]. Furthermore, the spin density of In is symmetrically distributed along In- $\mathrm{Zn}$ bond, which is the distinct characteristic of In-p orbital. Therefore, the impurity bands above the valance band maximum suggest that the hole doping mediates the magnetic coupling in In-doped ZnONSs.

\section{Conclusions}

In summary, we have studied the electronic structures and magnetic properties of IIIA group-doped $\mathrm{ZnO}$ nanosheets. Our results clearly demonstrate that the system's band gap increases along with the increase of the IIIA atom number due to the Goldschmidt-Pauling rule of bond contraction induced by undercoordination. The formation energies of $\mathrm{M}-\mathrm{Zn}$ are all smaller than $\mathrm{M}-\mathrm{O}$ and increases go along with the increase of the IIIA proton number for M-Zn. After Al-doped in the $\mathrm{ZnO}$ nanosheet, we find that the system shows half-metallic character and leads $\mathrm{ZnO}$ nanosheet to an n-type semiconductor. Ga-doped $\mathrm{ZnO}$ nanosheets shows metallic character with strong spin polarization. The half-metallicity is also found when In-doped in the $\mathrm{ZnO}$ nanosheets. The hole states resulting from In doped are spin-polarized and therefore lead to a high-spin state with a magnetic moment of about $0.97 \mu_{\mathrm{B}}$. The spin density of In is symmetrically distributed along In$\mathrm{Zn}$ bond, which is the distinct characteristic of In-p orbital and the impurity bands above the valance band maximum suggest that the hole doping mediates the magnetic coupling in In-doped $\mathrm{ZnONSs}$.

\section{Acknowledgments}

This work was supported by the National Natural Science Foundation of China (Grant nos. 61172028 and 61076088), the Natural Science Foundation of Shandong Province (Grant no. ZR2010EL017), the Doctor Foundation of University of Jinan (Grant no. xbs1043), Foundation for Young Scientist in Shandong Province (Grant no. BS2009CL012), and Technological Development Program in Shandong Education Department (Grant no. J10LA16).

\section{References}

[1] J. K. Furdyna, "Diluted magnetic semiconductors," Journal of Applied Physics, vol. 64, no. 4, article R29, 36 pages, 1988.

[2] T. Fukumura, Z. Jin, A. Ohtomo, H. Koinuma, and M. Kawasaki, "An oxide-diluted magnetic semiconductor: Mn-doped $\mathrm{ZnO,"}$ Applied Physics Letters, vol. 75, no. 21, pp. 3366-3368, 1999.

[3] H. Ohno, "Making nonmagnetic semiconductors ferromagnetic," Science, vol. 281, no. 5379, pp. 951-956, 1998.

[4] T. Dietl, H. Ohno, F. Matsukura, J. Cibert, and D. Ferrand, "Zener model description of ferromagnetism in zinc-blende magnetic semiconductors," Science, vol. 287, no. 5455, pp. 1019 1022,2000

[5] Z. L. Wang, "Piezopotential gated nanowire devices: piezotronics and piezo-phototronics," Nano Today, vol. 5, no. 6, pp. 540$552,2010$.

[6] Z. K. Tang, G. Wang, P. Yu et al., "Room-temperature ultraviolet laser emission from self-assembled $\mathrm{ZnO}$ microcrystallite thin films," Applied Physics Letters, vol. 72, no. 25, article 3270, 3 pages, 1998.

[7] M. Wang, K. E. Lee, S. H. Hahn et al., "Optical and photoluminescent properties of sol-gel Al-doped $\mathrm{ZnO}$ thin films," Materials Letters, vol. 61, no. 4-5, pp. 1118-1121, 2007.

[8] Y. S. Yu, G. Y. Kim, and B. H. Min, "Optical charactereistic of Ga doped ZnO compound," Applied Physics Letters, vol. 24, p. 1865, 2003.

[9] R. Wang, A. W. Sleight, R. Platzer, and J. A. Gardner, "Nonstoichiometric zinc oxide and indium-doped zinc oxide: electrical conductivity and ${ }^{111}$ In-TDPAC studies," Journal of Solid State Chemistry, vol. 122, no. 1, pp. 166-175, 1996.

[10] F. W. Xie, P. Yang, P. Li, and L. Q. Zhang, "First-principle study of optical properties of (N, Ga) codoped $\mathrm{ZnO}$," Optics Communications, vol. 285, p. 2660, 2012.

[11] I. V. Tudose, P. Horváth, M. Suchea, S. Christoulakis, T. Kitsopoulos, and G. Kiriakidis, "Correlation of $\mathrm{ZnO}$ thin film surface properties with conductivity," Applied Physics A, vol. 89, no. 1, pp. 57-61, 2007.

[12] C. Y. Zuo, J. Wen, S. L. Zhu, and C. Zhong, "The effect of C$\mathrm{Al}(\mathrm{Ga})$ codoping on p-type tendency in zinc oxide by firstprinciples," Optical Materials, vol. 32, no. 5, pp. 595-598, 2010.

[13] X. C. Liu, J. Y. Ji, Q. J. Zhao, Q. L. Liu, P. Z. Sun, and L. H. Dong, "First-principles study on electronic structure of Indoped wurtzite ZnO," Acta Physica Sinica, vol. 59, pp. 49254929, 2010.

[14] C. W. Zhang, S. S. Yan, P. J. Wang, P. Li, and F. B. Zheng, "Firstprinciples study on the electronic and magnetic properties of hydrogenated CdS nanosheets," Journal of Applied Physics, vol. 109, p. 094304, 2011.

[15] C. H. Liu, W. C. Yiu, F. C. K. Au, J. X. Ding, C. S. Lee, and S. T. Lee, "Electrical properties of zinc oxide nanowires and 
intramolecular p-n junctions," Applied Physics Letters, vol. 83, no. 15, pp. 3168-3170, 2003.

[16] X. Y. Kong, Y. Ding, R. Yang, and Z. L. Wang, "Single-crystal nanorings formed by epitaxial self-coiling of polar nanobelts," Science, vol. 303, no. 5662, pp. 1348-1351, 2004.

[17] W. Z. Wang, B. Q. Zeng, J. Yang et al., "Aligned ultralong $\mathrm{ZnO}$ nanobelts and their enhanced field emission," Advanced Materials, vol. 18, no. 24, pp. 3275-3278, 2006.

[18] M. H. Zhao, Z. L. Wang, and S. X. Mao, "Piezoelectric characterization individual zinc oxide nanobelt probed by piezoresponse force microscope," Nano Letters, vol. 4, no. 4, pp. 587-590, 2004.

[19] J. F. Conley, L. Stecker, and Y. Ono, "Directed integration of ZnO nanobridge devices on a Si substrate," Applied Physics Letters, vol. 87, no. 22, Article ID 223114, 3 pages, 2005.

[20] M. H. Wu, Y. Pei, and X. C. Zeng, "Planar tetracoordinate carbon strips in edge decorated graphene nanoribbon," Journal of the American Chemical Society, vol. 132, no. 16, pp. 5554-5555, 2010.

[21] D. B. Buchholz, R. P. H. Chang, J. H. Song, and J. B. Ketterson, "Room-temperature ferromagnetism in $\mathrm{Cu}$-doped $\mathrm{ZnO}$ thin films," Applied Physics Letters, vol. 87, no. 8, Article ID 082504, 3 pages, 2005.

[22] Z. C. Tu, "First-principles study on physical properties of a single $\mathrm{ZnO}$ monolayer with graphene-like structure," Journal of Computational and Theoretical Nanoscience, vol. 7, no. 6, pp. 1182-1186, 2010.

[23] M. Topsakal, S. Cahangirov, E. Bekaroglu, and S. Ciraci, "Firstprinciples study of zinc oxide honeycomb structures," Physical Review B, vol. 80, no. 23, Article ID 235119, 14 pages, 2009.

[24] X. F. Wang, X. S. Chen, R. B. Dong, Y. Huang, and W. Liu, "Ferromagnetism in carbon-doped $\mathrm{ZnO}$ films from first-principle study," Physics Letters A, vol. 373, no. 34, pp. 3091-3096, 2009.

[25] W. H. Zhang, F. C. Zhang, Z. Y. Zhang, J. F. Yan, and J. N. Yun, "Theoretical investigation on electronic and optical properties of $\mathrm{ZnO}$ doped with $\mathrm{Al}, \mathrm{Ga}$ and In," Journal of Functional Materials and Devices, vol. 15, no. 2, pp. 153-158, 2009.

[26] X. J. Liu, Z. F. Zhou, L. W. Yang et al., "Correlation and size dependence of the lattice strain, binding energy, elastic modulus, and thermal stability for Au and Ag nanostructures," Journal of Applied Physics, vol. 109, no. 7, Article ID 074319, 5 pages, 2011.

[27] S. B. Zhang and J. E. Northrup, "Chemical potential dependence of defect formation energies in GaAs: application to Ga selfdiffusion," Physical Review Letters, vol. 67, no. 17, pp. 2339-2342, 1991.

[28] E. Z. Liu and J. Z. Jiang, "Magnetism of O-terminated $\mathrm{ZnO}(0001)$ with adsorbates," Journal of Physical Chemistry C, vol. 113, no. 36, pp. 16116-16120, 2009. 

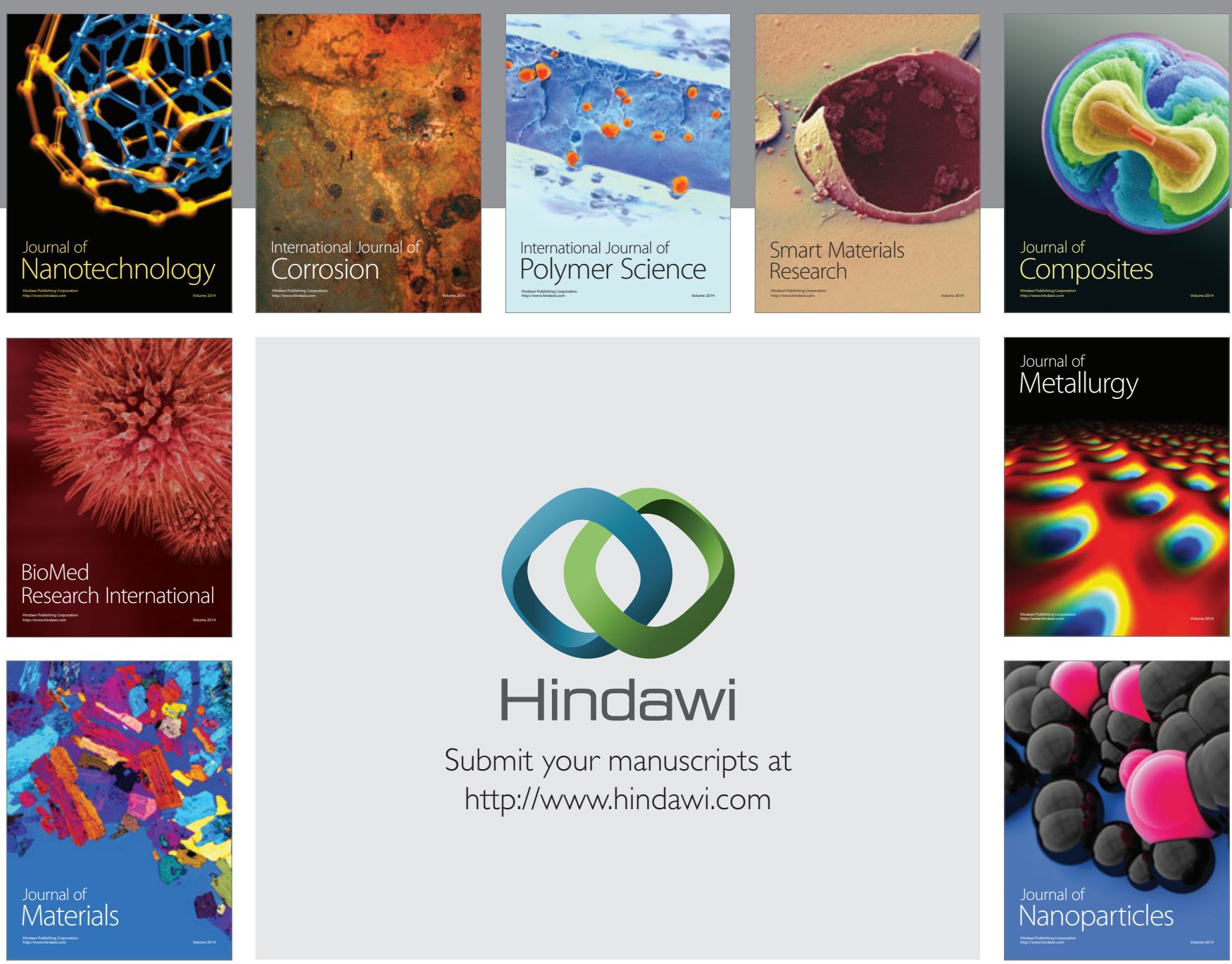

Submit your manuscripts at http://www.hindawi.com
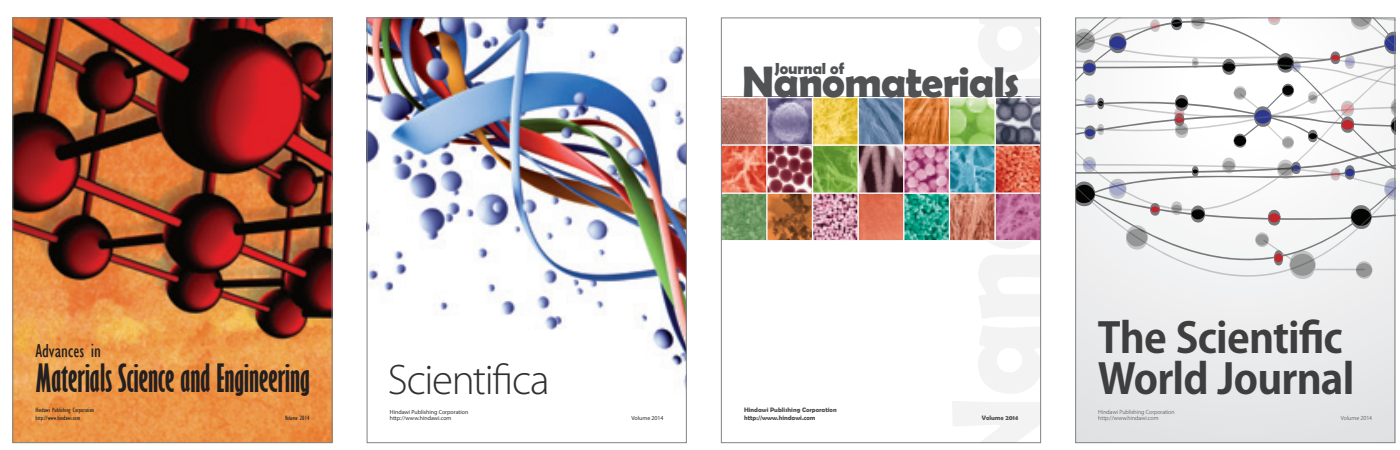

\section{The Scientific World Journal}
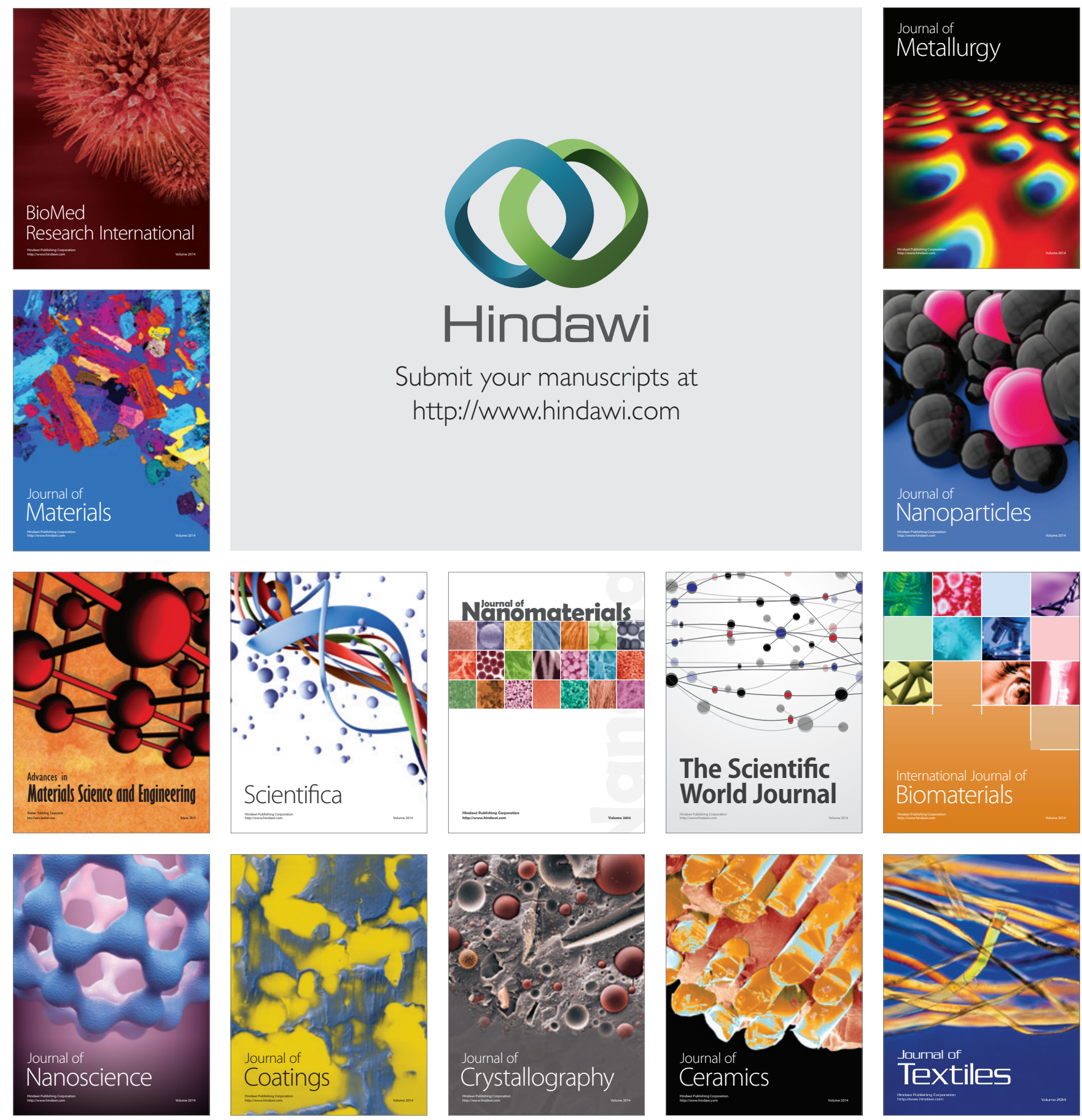